\title{
O TEXTO EM AULA DE LÍNGUA PORTUGUESA
}

Elisa Guimarães*

RESUMO: O trabalho com o texto em aula de Língua Portuguesa deve despertar a consciência dos recursos múltiplos da Língua - recursos cuja exploração redunda em garantia de uma competência discursiva ligada à competência lingüística. Presta-se, pois, o texto à consolidação e aperfeiçoamento de uma posse ativa da Língua, ou seja, da capacidade de receber e produzir, de forma adequada, discursos diferenciados em situações de comunicação também diferenciadas.

Palavras-chave: Texto, discurso, língua em funcionamento, competência lingüística, comunicação.

A procura de uma definição satisfatória para texto torna possível uma reflexão sobre sua bidimensionalidade: enquanto processo discursivo, enquanto trajetória estrutural, um texto é acabado; enquanto campo semântico, dada a expansão desse campo, o texto é inesgotável.

Tem-se, pois, a um só tempo, um processo linear com encerramento e um processo de folheamento vertical - aberto, conseqüentemente -, o que deve ser levado em conta no exercício de abordagem do texto.

A noção de abordagem implica a concepção de texto não apenas como um dado, como algo que é trazido para a sala de aula, mas como um valor que também se produz na própria aula.

Utilizá-lo na simples função valorativa de exemplo, ou atribuir-lhe função apenas ilustrativa como forma de preencher uma determinada unidade temática é negar-lhe a condição primordial de repositório das virtualidades da Língua.

É no texto, nas suas diferentes modalidades, nas diversas possibilidades de ser interpretado e produzido, que se recuperam fatos reais da Língua em funcionamento.

* Universidade de São Paulo. 

1996.

Só o texto aponta para a descoberta paulatina de noções, de relações, de conceitos com os quais se opera na teoria do texto e na teoria gramatical para - em necessária sintonização - pesquisar a linguagem como objeto de reflexão e estudo.

Mais do que sobre a linguagem, o tratamento com a linguagem deve preencher a aula de Língua Portuguesa. A interpretação e a análise a serem aí efetivadas não podem circunscrever-se à reflexão gramatical ou a ela conceder predomínio.

Trata-se, antes, de adquirir capacidade de expressão, isto é, de desenvolver plenamente a competência comunicativa do aluno. O objetivo precípuo é levá-lo a usar melhor a Língua, não apenas como aperfeiçoamento de tipo estrutural, como correção de estruturas, como aquisição de estruturas novas, mas para alcance em plenitude de adequação do ato verbal à situação de comunicação.

Assim, à luz da didática da língua materna, o texto como objeto de trabalho desperta a consciência dos recursos múltiplos da Língua - recursos cuja exploração redunda em garantia da aquisição de uma competência discursiva aliada à competência lingüística.

Presta-se, pois, o texto à consolidação e ao aperfeiçoamento de uma posse ativa da Língua, ou seja, da capacidade de receber e produzir, de forma adequada, discursos diferenciados em situações também diferenciadas de comunicação.

Já se vem afirmando, há pelo menos duas décadas, um movimento de valorização do texto fundamentado em recentes propostas da Lingüística Textual, segundo as quais uma descrição-explicação do funcionamento da Língua que se detenha no nível da frase é manifestamente insuficiente para servir de base teórica ao ensino-aprendizagem do funcionamento do texto.

De fato, a competência textual é uma competência específica e não um mero alargamento de uma competência frásica, uma vez que, realizando-se embora numa seqüência de frases, o texto configura-se numa unidade global, como um todo, dando expressão a uma intenção comunicativa unitária.

É esta a visão a ser transmitida ao aluno em sala de aula de Língua Portuguesa, quando no desempenho das atividades de leitura, de interpretação e de redação - atividades que o situam na confluência das relações dinâmicas que constróem o texto, relações que se corporificam nos mecanismos seguintes:

a - No texto à luz da construção da linguagem e da organização da estrutura textual; 

1996.

$\mathrm{b}$ - No contexto - que, próximo ou longínquo, interno, ou externo refere-se ao jogo das implicações não formuladas, pois que um texto acumula sobre cada enunciado, num dado momento de seu desenvolvimento, uma seleção das informações que o precederam ou que a ele se seguiram; c - No intertexto - que aponta para o jogo das transferências implícitas ou explícitas de texto para texto.

Dessas relações resulta o multifuncionalidade do texto, permitindo a riqueza do discurso e oferecendo um arsenal de dados para a garantia da transmissão e da assimilação da mensagem.

Em cada nova situação, um contexto a exigir orientação específica e especializadora - um significado novo recontextualizando significados anteriores, determinando a especialidade e a especificidade de cada uma das faces do tema proposto ao exercício de leitura, de análise e de crítica.

Essas mesmas relações tornam, pois, possível a visão do texto na sua dupla natureza de atividade e objeto - atividade comunicativa e atividade cognitiva - ao mesmo tempo que objeto sobre o qual se pode sistematizar e categorizar.

O dinamismo das relações que constróem o texto permite ainda a visão da leitura e da produção de texto como dois momentos complementares do estudo e da atividade didática. Ou como dois pólos de um mesmo processo pragmático: no primeiro caso, parte-se do texto a ler e a analisar para uma reconstituição das coordenadas situacionais a que ele se liga e às quais se deve adequar ; no segundo caso, parte-se das situações para levar a uma criação do texto, a uma produção que procura adequar-se às circunstâncias previamente dadas.

Tais exercícios visam ao aperfeiçoamento da competência comunicativa, alargando-a e matizando-a, por meio da sensibilização às características especificas de cada tipo de texto.

Torna-se, portanto, indispensável considerar, para além de uma gramática da frase, uma gramática do texto e proceder a uma exploração pedagógica dessa gramática que se orienta para uma ainda mais alargada gramática da comunicação.

De fato, aceito o princípio de que só o texto reflete todos os fenômenos envolvidos no ato da comunicação, e uma vez que a gramática frasal não dá conta de muitos fatos de natureza lingüística, estes devem ser abarcados por um programa de gramática textual.

Pense-se, a título de exemplo, nas lacunas da gramática de frase em relação ao tratamento de fatos, como a correferência, a pronominalização, a 

1996.

ordem das palavras no enunciado, a relação tópico/comentário ou tema/rema, as relações entre frases não ligadas por conectivos, o uso dos tempos verbais explicado em termos de texto. Pense-se ainda, a título de exemplo, nas lacunas da gramática frasal com referência ao contexto situacional - fator poderosamente elucidativo da carga semântica do texto. O que se faz, pois, necessário é uma maior preocupação com problemas morfológicos, lexicais, sintáticos e semânticos extraídos de um corpus mais extenso do que a frase, para a fixação de uma gramática do texto.

A variedade de mundos que se codificam, recodificam e descodificam no espaço textual torna complexo e multirreferencial o texto - o que, talvez, explique, em parte ao menos, a dificuldade do aluno em saber onde, como e por que se configura essa complexidade.

O convívio com o texto rasga, pois, horizontes no processo de desvendamento dos traços configuradores da dimensão lingüístico- discursiva da realidade textual.

Em aula de Língua Portuguesa - certamente mais do que em qualquer outro espaço - o texto dever ser instrumento de observação, de análise e até mesmo de fruição dos domínios da Língua.

Exibe o texto um movimento complexo dos usos lingüísticos entretecidos às mais diversas formas do fazer e do prazer do autor.

Não nos parece, pois, despropositado conjugar o papel do texto com a possibilidade de uma relação lúdico-afetiva em que a Língua, através do mesmo texto, é simultaneamente expressão e objeto de desejo e de fruição.

Completa se nesse campo - o do sentimento - a relação intelectual em que a Língua é, a um tempo, meio e objeto de conhecimento.

Uma e outra relação comprometem-se ainda com a dimensão hipertextual do texto que se corresponde sempre com outros textos, traçando, por isso, uma rede de intertextualidade - cuja captação é fator importante no exercício de interpretação do texto.

É, pois, múltiplo o domínio das relações textuais - o que se comprova ainda pela sensibilização aos laços de interdependência entre texto e contexto - o âmbito sócio-histórico que o envolve e lhe atribui sentido.

A leitura e a produção de textos estão condicionadas ao conhecimento das circunstâncias que os motivam.

Considerado o texto à luz de uma função pragmática, isto é, dentro das finalidades de informação a que se destina, é válido insistir na idéia de que todo e qualquer texto existe numa situação comunicativa. E tanto mais esse texto cumprirá sua função, quanto mais atingir um nível de significação em relação a esse contexto comunicativo. 
De fato, é privilégio dessa interdependência a captação das características do espaço comunicativo com o qual o texto se articula, bem como a apreensão das decisões discursivas sucessivas às quais ele dá lugar.

No entanto, o peso das considerações de ordem sociológica não pode, não obstante sua importância, relegar para segundo plano o processo de construção lingüística do texto - interesse primeiro de uma aula de Língua Portuguesa.

Courtine pressupõe que

"o texto materializa o contato entre o ideológico e o lingüístico no sentido de que ele representa no interior da Lingua os efeitos das contradições ideológicas" (Courtine, 1982/240).

Lembra ainda Schmidt (Schmidt, 1978/168-196) que

"os textos têm uma relevância sócio-comunicativa na medida em que a textualidade do ato comunicativo, a título de instituição social, vem constituir um elo entre a interação social e o encadeamento de elementos lingüísticos"

Concebe-se, assim, o texto como produto determinado e definível simultaneamente no nível lingüístico e no nível social - o que exclui a sua concepção como estrutura puramente verbal e abordável exclusivamente por fatores lingüísticos.

Há, portanto, como estabelecer harmoniosa conjugação: propondo-se como objetivo o desenvolvimento da competência discursiva, o ensino da Língua deixa de restringir-se à competência lingüística - o que, contudo, não significa que deve ser esquecido o componente lingüístico da competência discursiva. Significa, isso sim, que é necessário alargar o seu âmbito à luz da relevância que deve ser dada aos mecanismos de construção do texto.

Assim, é preciso atribuir um lugar de destaque ao conjunto dos procedimentos lingüísticos e discursivos que fundamentam a estabilidade e a homogeneidade do texto.

Tenha-se, por exemplo, o parágrafo como ponto centralizador dos diferentes movimentos que dinamizam o texto: o movimento cronológico, o qual descreve etapas, operações que se sucedem no tempo; o movimento em cadeia, em que intermediários bem concertados fazem desembocar idéias 

1996.

simples em idéias complexas; o movimento em leque, onde se verifica o alongamento da idéia aplicado a domínios diversos - fato que ocorre em textos antes de tudo descritivos e técnicos; o movimento em ondas, cujo ponto inicial, à força de aproximações com outros fatos ou idéias, faz desembocar as reflexões numa idéia geral proposta como conclusão.

No texto em geral, a cadeia das idéias, as unidades de sentido distribuem-se segundo o movimento que o autor pretende dar à sua exposição.

Acentua-se, pois, a função do parágrafo enquanto espaço onde se distribuem os fatores de coesão estrutural, bem como os de coerência conceptual.

É, por conseguinte, de suma importância que nos processos constituintes da organização do texto se dê especial relevo à maneira como se integram, se estruturam, se combinam e se desenvolvem no texto os elementos que garantem a coesão e a coerência discursiva.

A percepção desses mecanismos, decorrente do trabalho com o texto em classe, acaba por inspirar ao aluno uma certa disciplina mental de abordagem - fato do qual decorre a transformação desse aluno num leitor ativo, ou seja, capaz de julgar o texto, de relacioná-lo, de analisá-lo adequadamente.

Aqui, pensa-se na leitura, na operacionalização das atividades de leitura para a produção de texto.

A leitura adulta é, naturalmente, uma atividade que envolve elaborações semânticas, pragmáticas, lógicas e culturais. Depende de uma série de fatores lingüísticos e extralingüísticos, sendo algo muito mais complexo do que a simples decifração de um suposto sentido literal.

O tipo de processo utilizado no ato de ler depende de várias condições:

a - do grau de maturidade do sujeito como leitor;

$\mathrm{b}$ - do nível de complexidade do texto;

c - do objetivo da leitura;

$\mathrm{d}$ - do grau de conhecimento prévio do assunto tratado;

$\mathrm{e}$-do estilo individual do leitor.

No processo de captação das linhas organizadoras, bem como das linhas definidoras da significação do texto, há etapas progressivas. A trajetória pelas linhas e entrelinhas, pelo dito e pelo "não-dito" (emprestada a já consagrada expressão de Ducrot) cumpre-se num trajeto que se estende da compreensão referencial à leitura crítica. A sintonia dos dois processos 
significará a leitura madura, produtiva. Os dois exercícios - o de leitura e o de produção de texto - ter-se-ão efetivado, por exemplo, em torno de uma leitura que permita resposta às questões como as seguintes, imaginando-se ter como instrumento de trabalho um texto dissertativo:

- A posição do autor em relação ao objeto do discurso é: favorável/ neutra/desfavorável.

- A posição do autor é significativa: de uma atitude individual/de grupo social/de uma comunidade cultural/nacional.

- A distância entre o autor e o objeto do seu discurso é: nula (autor muito implicado)/média (autor pouco implicado)/grande (autor pouco ou nada implicado).

- O objetivo do discurso é: reforçar uma adesão/modificar a atitude do leitor

- Os argumentos são: convincentes/fracos/completos/falhos.

O discurso no conjunto parece: eficaz/pouco eficaz. Percorrendo as etapas da produção de leitura, o leitor armazena um referencial significativo de idéias, capacitando-se, assim, para a produção textual, a qual, por sua vez também exige uma metodologia própria.

Esta parece ser a via indicada para guiar o aluno na tarefa de (re)construção da textualidade, entendida como

"la cohérence particulière qui fait qu un texte est un texte" (Weinrich, 1989/25).

Ou a textualidade entendida como a rede de relações que faz com que um texto não se reduza a uma simples somatória de frases; antes, revela uma conexão entre as intenções, as idéias e as unidades lingüísticas que o compõem, por meio do encadeamento de enunciados dentro do quadro estabelecido pela enunciação (Halliday, 1976).

É este ainda o caminho proposto para, em aula de Língua Portuguesa, orientar o aluno no sentido de operar, não tanto sobre a linguagem, mas com a linguagem, por meio de textos produzidos por ele próprio.

O exercício de produção de texto oferece margem para a aplicação da multiplicidade de recursos existentes na Língua; completa, por isso, o exercício de captação, de análise e de interpretação dessa mesma multiplicidade.

Por sua vez, a consonância desses dois exercícios propõe-se como instrumento eficaz de transformação do aluno em sujeito de produção - pro- 

1996.

posta de extrema conveniência, se não de indiscutível necessidade, uma vez que a atual tecnologia de comunicação rouba praticamente do aluno a oportunidade de convivência com a palavra escrita.

Acrescente-se a esse fato a possível ocorrência do risco de se estar formando lingüistas que não tenham domínio do próprio desempenho lingüístico na modalidade escrita.

Das reflexões até aqui apresentadas, parecem válidas duas inferências:

1 - a importância do trabalho com o texto - unidade maior de investigação da Língua em funcionamento, na aula de Português, onde a mesma Língua é simultaneamente o meio, o objeto e o objetivo;

2 - as incidências do trabalho com o texto na definição da função do professor de Lingua Portuguesa.

Esta segunda inferência é um convite à avaliação do alcance da atuação didática do professor de Língua Portuguesa, bem como da especificidade de sua função em sala de aula, enquanto disciplinador da atividade do aluno no trabalho com o texto.

Detenhamo-nos ainda na importância desse fato. O caráter específico da aula de Língua materna coloca-a naturalmente numa situação particular em confronto com as outras disciplinas, no sistema curricular. É que, por um lado, o objeto de estudo é inseparável do meio de transmissão do conhecimento a ser adquirido em aula; por outro lado, esta transmissão ganha aqui um estatuto igualmente singular: não se transmite uma técnica - a competência comunicativa - como se transmite o conhecimento de dados, de noções ou mesmo de metodologia. Quer dizer, o tipo e a natureza do conhecimento procurado na aula de língua materna é diverso do procurado nas demais disciplinas. Mais que isso: a pedagogia moderna procura substituir a transmissão pura de saber adquirido pela indagação, pela autêntica construção do saber pelos alunos. Ora, é justamente esta a situação natural para a aquisição da linguagem; é sobre o exercício e sobre a observação da prática lingüística, em que naturalmente está mergulhado, que o aluno constrói o seu saber lingüístico. Interiorizar a técnica lingüística é exatamente descobrir, com os instrumentos e mecanismos atualizados na comunicação, a organização da Lingua, as suas funções, as condições de utilizá-la - o que se fará não tanto pela transmissão, do professor para o aluno, de conhecimentos vazados em modelos teóricos, mas na produção real, na observação sistemática. Na aquisição do saber lingüístico como domínio de linguagem ori- 
entado para a comunicação, haverá construção individual, criação, isto é, autêntica assimilação da Língua. Conciliemos esta idéia com uma reflexão acerca do ensino da gramática.

Esta questão vem polarizando as atenções e constituindo-se como de grande importância na pedagogia de Línguas - fato que talvez se explique por dois fatores fundamentais:

1 - a sólida tradição de uma reflexão de tipo histórico, filosófico e lógico sobre a linguagem (a que se agrega não raro a ilusão de que o ensino da gramática disciplina ou "forma" o pensamento);

2 - a insistente divulgação da Lingüística do sistema, com que se articula o pendor metalingüístico do ensino da Língua que sobrevaloriza na aquisição da linguagem o conhecimento do sistema formal. Subjacente a este pendor está a convicção de que o domínio das dimensões sociais e individuais do uso da linguagem advirá naturalmente com esse conhecimento: uma vez conhecido o código, automaticamente se cumpririam as funções para as quais este está orientado - o que não só não é linear, como também é desmentido pela prática. Tal pretensão é nitidamente reveladora da incorreta avaliação daquelas dimensões como algo de exterior, de derivado, de acrescentado à verdadeira natureza do objeto linguagem. No processo de uso da língua, não podemos separar uma competência lingüística e uma competência pragmática, ambas associadas e reciprocamente influentes na competência comunicativa. Logo, não pode o professor de Português "ensinar" a Língua no aspecto estrutural, aguardando que naturalmente se siga o uso adequado. É, antes, o uso adequado e eficaz que deve ser interiorizado cumulativamente com os instrumentos e seus valores. Em suma: interiorizam-se não apenas as regras da "boa formação" de frases (e, mais que de frases, de discursos), mas igualmente as regras da "boa execução"

O trabalho com mais do que sobre a linguagem, já o dissemos, deve esgotar, preencher a aula de Língua Portuguesa.

A aula de Português é antes de tudo e sempre aula de língua. Tratase, pois, de adquirir capacidade de expressão, isto é, de desenvolver e estruturar plenamente a competência comunicativa.

Nessa situação lingüística mais desenvolta, o aluno realizará uma mais completa integração na práxis social - o que se efetiva numa dupla perspec- 

1996.

tiva: como emissor, o aluno estará em condições de tomar consciência das coordenadas e seu lugar relativo - que suscitam e marcam o seu discurso; como receptor, será sensível às determinantes do valor de comunicação de cada enunciado, e desenvolverá o seu espírito crítico perante o discurso alheio.

Como falante que é, o aluno já está inserido nas grandes linhas desta problemática, antes de iniciar o estudo da Língua. Compete ao professor sistematizar, para ele, intencionalmente, a variedade de discursos com que já conviveu, levando-o a apreender as determinantes dessa variedade. Compete ao professor fomentar no aluno a capacidade de adequar o seu desempenho lingüístico às situações concretas de comunicação.

Isto leva-nos diretamente a considerar, no plano prático, a utilização do texto na aula de Português. Há que passar por dentro do texto. Neste aspecto, muito devemos ao estruturalismo. Há que passar pelo meio do texto, sabê-lo abrir em cada uma das partes, uma vez que, se perdemos o sentido do rigor das articulações, nunca produziremos um texto aberto.

Uma das funções do professor de Português é, pois, exigir e ao mesmo tempo ensinar as articulações do texto.

Com vistas à relação entre prática científica e prática pedagógica, que o professor de Português se dê por recompensado, se vier a transformar o aluno em sujeito de produção. Tomemos o caso especifico do texto literário. Há duas realidades distintas no campo da literatura: uma é o texto literário, outra, o discurso organizado que se produz sobre o texto literário. Nesta segunda prática, evidentemente, há uma margem de indecisão entre um discurso organizado de uma certa maneira, que pode ser o ensaio, que pode ser a crítica, que pode ser o comentário. Há ainda o próprio texto literário que pode justamente não conter perspectivação crítica ou ensaística.

Cremos ser extremamente importante podermos incluir na prática dos exercícios dos alunos do Curso de Letras uma dimensão de construção de um texto enquanto realmente objeto literário. É sempre com o mais vibrante entusiasmo que escrevemos à margem de uma página literária produzida pelo aluno: "verdadeira vocação para a arte de escrever. É preciso explorar o talento"...

Talvez aqueles que se dedicam exclusivamente a um ato segundo, portanto de análise e não de produção de textos, queiram objetar que não existe produção de texto que não seja análise de outro tex to já constituído. A objeção será pertinente, desde que fique esclarecido que a análise de um texto não se realiza sem a produção de outro texto, regressando-se, assim, à prioridade da constituição, relativamente à análise. 

1996.

A jeito de parênteses e a propósito dessa última idéia: é conveniente, em sala de aula de Língua Portuguesa, evitar a atitude de análise que não conduz - ou conduz pouco - à produção de textos - o que contribui, certamente, para a formação de escolares que não ultrapassam o plano da profissão de comentadores livres, avulsos, verbalistas, sem se comprometerem com a produção de textos, onde se espelharia o seu mundo.

A inflexão da análise de textos para a produção dos mesmos carregase de conseqüências escolares e científicas, das quais destacamos:

1) a necessidade de se considerar o ensino como um ato de produção de textos. Nenhuma oralidade nem uma multidão de trabalhos escritos esparsos substituem o ato e a dimensão do mundo referenciado pela unidade e densidade de uma dissertação, por exemplo;

2) a insistência sobre o exercício constituinte dos textos - que não a mera análise deles - é a melhor forma de promover a unidade do saber e da aproximação de todos aqueles que ao saber se dedicam, ultrapassando, desse modo, a aprendizagem passiva e redutora. É a produção de textos o caminho mais fecundo, além de insubstituível, da análise de textos.

Em todas essas perspectivas relacionadas com o texto, define-se e firma-se a função do professor de Língua Portuguesa.

\section{BIBLIOGRAFIA}

BRONCKART et alii. Le Fonctionnement des Discours. Neuchâtel et Paris, Delachaux et Niestlé, 1995.

COURTINE, J.J. "Definitions d' orientations théoriques et construction de procédures en analyse du discours" In: Philosophiques, Vol. IX, n 2 , octobre, 1982.

FONSECA, Fernanda Irene. Gramática e Pragmática. Estudos de Lingüistica Geral e de Lingiïística Aplicada ao Ensino de Português. Porto, Porto Editora, 1994.

FONSECA, Joaquim. Pragmática Lingüistica. Introdução, Teoria e Descrição do Português. Porto, Porto Editora, 1994.

HALLIDAY, M.A. e HASAW, R. Cohesion in English. London, Longman, 1976. SCHMIDT, J. Siegfried. Lingüistica e Teoria de Texto. Trad. de Ernst F. Schurmann. São Paulo, Livraria Pioneira Editora, 1978.

WEINRICH, H. Grammaire Textuelle du Français. Paris, Didier / Hatier, 1989.

ABSTRACT: The purpose of the work on texts, in the lessons of Portuguese 

1996.

language in classroom, is to arouse the consciousness about the multiple means, whose exploration leads to the assurance of discoursive competence connected to linguistic competence.

Therefore, the text helps to improve and solidify the active command of the language, that is, the aptitude to receive and produce, with adequacy, different kinds of messages in different circumstances of communication.

Key Words: Text, discourse, language in function linguistic competence , communication. 